\title{
Case Report \\ Successful Treatment of Myeloid Sarcoma in an Elderly Patient with Myelodysplastic Syndrome with Reduced-Dose Azacitidine
}

\author{
Kazuya Sato $\mathbb{D}^{1},{ }^{1}$ Nodoka Tsukada ${ }^{\mathbb{D}},{ }^{1}$ Junki Inamura, ${ }^{1}$ Shigetsuna Komatsu, ${ }^{2}$ Keisuke Sato, $^{3}$ \\ Masayo Yamamoto $\unrhd,{ }^{4}$ Motohiro Shindo $₫,{ }^{4}$ Kentaro Moriichi $₫,{ }^{4}$ Yusuke Mizukami $₫{ }^{4}{ }^{4}$ \\ Mikihiro Fujiya $\left(\mathbb{D}^{4}{ }^{4}\right.$ Yoshihiro Torimoto, ${ }^{4}$ and Toshikatsu Okumura $\oplus^{4}$ \\ ${ }^{1}$ Department of Hematology/Oncology, Asahikawa Kosei General Hospital, 1-24, Asahikawa 078-8211, Japan \\ ${ }^{2}$ Department of Dermatology, Asahikawa Kosei General Hospital, 1-24, Asahikawa 078-8211, Japan \\ ${ }^{3}$ Department of Clinical Laboratory, Asahikawa Kosei General Hospital, 1-24, Asahikawa 078-8211, Japan \\ ${ }^{4}$ Division of Gastroenterology and Hematology/Oncology, Department of Medicine, Asahikawa Medical University, Asahikawa, \\ Hokkaido, Japan
}

Correspondence should be addressed to Kazuya Sato; satofam@wine.plala.or.jp

Received 16 November 2020; Revised 6 April 2021; Accepted 13 April 2021; Published 22 April 2021

Academic Editor: Sudhir Tauro

Copyright (C) 2021 Kazuya Sato et al. This is an open access article distributed under the Creative Commons Attribution License, which permits unrestricted use, distribution, and reproduction in any medium, provided the original work is properly cited.

\begin{abstract}
Myeloid sarcoma (MS), which involves extramedullary lesions, is classified as a unique subtype of acute myeloid leukemia (AML). At present, no standard treatments for MS have been established. The patient was an 89-year-old man with myelodysplastic syndrome-excess blast-2 (MDS-EB-2) with a 2-year history of intermittent treatment with azacitidine (AZA) during a 4-year history of MDS. He developed painful cutaneous tumors 8 months after the second discontinuation of AZA. They were refractory for antibiotics and topical tacrolimus hydrate. A tumor biopsy was performed, and the histological findings of the tumor lesion showed a proliferation of tumor cells that were positive for myeloperoxidase and CD68 and negative for CD4 and CD123. The patient was diagnosed with MDS-associated MS. MDS-EB-2 quickly progressed to AML with the appearance of peripheral blood blasts and 25\% bone marrow blasts. Monotherapy with reduced-dose AZA ( $37.5 \mathrm{mg} / \mathrm{m}^{2}$ for 7 days, every $4-6$ weeks) was restarted, and the MS quickly disappeared. The patient's MS was successfully treated with 16 cycles of AZA treatment over a 22-month period. There have been 10 reported cases in which MS was successfully treated with AZA. Among the 10 cases, the patient in the present case was the oldest. Treatment with reduced-dose AZA should be considered as a therapeutic option for MS in elderly patients with MDS, especially patients who are ineligible for intensive chemotherapy.
\end{abstract}

\section{Introduction}

Myeloid sarcoma (MS), which involves extramedullary lesions at sites such as the skin, lymph nodes, gastrointestinal tract, bone, soft tissue, and testis, is classified as a unique subtype of acute myeloid leukemia (AML) [1-3]. MS may precede or coincide with AML or represent acute blastic transformation of myelodysplastic syndrome (MDS), myeloproliferative neoplasms, or chronic myelogenous leukemia $[1,2,4]$. No standard treatment for MS has been established; thus, intensive chemotherapy consisting of anthracycline and cytarabine is generally selected as the initial therapy, according to chemotherapy for AML. In addition, allogeneic hematopoietic stem-cell transplantation (allo-HSCT) or radiation therapy may also be considered $[2,4]$. However, elderly patients are generally not eligible for intensive chemotherapy and allo-HSCT; thus, further strategies are required, especially for elderly patients with MS.

A hypomethylating agent, azacitidine (AZA), which improved overall survival in comparison to conventional care treatment in higher-risk MDS patients who were not eligible for allo-HSCT [5], is widely used in clinical practice for the treatment of patients with MDS, as well as a proportion of patients with AML $[6,7]$. However, there are few 
reports of patients with MS who were successfully treated with AZA [8-13].

We herein report a case of MS in an elderly patient with MDS, which was successfully treated with 16 cycles of AZA treatment over a 22-month period. This is a rare case of MS that was successfully treated with AZA monotherapy.

\section{Case Presentation}

An 85-year-old man with pancytopenia was diagnosed with MDS with multilineage dysplasia (MDS-MLD) based on bone marrow aspiration (BMA), which revealed 2.6\% myeloblasts with trilineage dysplasia and normal karyotype. Based on these findings, the case was categorized as intermediate-1 or low risk according to the International Prognostic Scoring System (IPSS) [14] or Revised IPSS (IPSS-R) [15], respectively. At this point, the patient had been treated with vitamin K2 (menatetrenone) and active vitamin D3 (calcitriol) because combination therapy of these two drugs was reported to be effective against low-risk MDS [16]. At 87 years of age, the patient undertook BMA again because his pancytopenia had progressed, and he was diagnosed with MDS with excess blasts-2 (MDS-EB-2) based on the BMA findings, which revealed $11 \%$ myeloblasts and multilineage dysplastic changes of bone marrow cells (Figures 1(a)-1(d)), with a normal karyotype. The disease status was categorized as intermediate- 2 risk according to the IPSS and high risk according to the IPSS-R; thus, AZA treatment was initiated on hospitalization at the standard dose of $75 \mathrm{mg} / \mathrm{m}^{2} /$ day, subcutaneously, for 7 days every month. The patient achieved a hematological improvement (HI) with manageable adverse events (AEs), including constipation and general malaise after the first cycle of AZA. The second cycle was therefore administered in an outpatient setting. However, the treatment was discontinued due to septic shock after the second cycle of AZA. The patient became dependent on red blood cell (RBC) transfusions due to a clinical progression of MDS because one year after the discontinuation of AZA (at 88 years of age), we did not perform any histological examinations, such as BMA. Therefore, additional 3 cycles of AZA were administered in an outpatient setting with a reduced dose of $37.5 \mathrm{mg} / \mathrm{m}^{2}$ (50\% dose reduction) daily. The dose of AZA was decided according to the prescribing information for AZA [17] based on the nadir absolute neutrophil count $<0.5 \times 10^{9} / \mathrm{L}$ in the preceding (second) cycle. Treatment with AZA was discontinued again because the patient refused to continue the treatment due to the AEs, which included constipation and general malaise, as well as the inconvenience of going to the hospital.

At eight months after the second discontinuation of AZA (at 89 years of age), a painful cutaneous tumor, the top of which showed yellow-colored necrosis (Figure 2(a)), developed at the left groin lesion. Laboratory tests revealed the following: white blood cell count, $2,900 / \mu \mathrm{L}$, with $63.6 \%$ neutrophils, $32.6 \%$ lymphocytes, $3.5 \%$ monocytes, $0.3 \%$ eosinophils, and no blast cells; hemoglobin, $6.6 \mathrm{~g} / \mathrm{dL}$; platelet count, $8.7 \times 10^{4} / \mu \mathrm{L}$; and C-reactive protein, $0.57 \mathrm{mg} / \mathrm{dL}$. No treatments, including oral and topical antibiotics, topical tacrolimus hydrate, and analgesics, had any effect on the tumor. A biopsy of the tumor was performed one month after its development. Histological examination revealed the proliferation of tumor cells with a high nuclear/cytoplasmic ratio (Figure 3(a)). Immunohistochemically, the neoplastic cells were positive for myeloperoxidase (Figure 3(b)), partially positive for cluster of differentiation (CD) 68 (Figure 3(c)) and CD33, but negative for CD3, CD4 (Figure 3(d)), CD20, CD34, CD56, CD117, and CD123 (Figure 3(e)). A diagnosis of MDS-associated MS was made. One month after the development of the first cutaneous lesion, another cutaneous tumor appeared on the left cheek (Figure 2(b)). BMA revealed a hypercellular marrow with $25 \%$ myeloblasts, which were positive for CD13, CD33, CD34, and HLA-DR; a G-band analysis revealed a normal karyotype. A diagnosis of AML secondary to MDS was made.

Considering the patient's age, clinical conditions, and the previously experienced AEs, treatment with AZA was started again at a dose of $37.5 \mathrm{mg} / \mathrm{m}^{2} /$ day, subcutaneously, for 7 days every 4-6 weeks (in total, this was the $6^{\text {th }}$ cycle of AZA treatment) during short-term hospitalization, which consisted of 9 days of inpatient treatment per cycle, in order to manage the acute-phase AEs caused by AZA. The cutaneous MS lesion located on the left groin (Figures 4(a)-4(c)) and that on the left cheek (Figures 4(d)-4(f)) promptly disappeared after the $6^{\text {th }}$ and $7^{\text {th }}$ cycles of AZA treatment. Although myeloblasts had appeared in peripheral blood after several cycles of retreatment with AZA, the treatment was continued because of persistence of the response on MS, and the pain caused by his lesions remained relieved, with tolerable AEs, by AZA. The patient had received 16 cycles (over a 22-month period) of AZA treatment with the same dose on repeated short-term hospitalization until he died of progression of AML. He eventually received 21 cycles of AZA treatment in total. No exacerbation of cutaneous MS had been confirmed during AZA treatment.

\section{Discussion}

We experienced a case of MS in an elderly man with MDS, which was successfully treated with AZA over a 22-month period. Although cytarabine-based intensive chemotherapy is generally selected as the initial therapy for MS (based on its efficacy) [2,3], the patient in the present case was 89 years of age, and there were concerns about AEs. Radiation therapy may be a therapeutic option for MS; however, the patient had already developed multiple MS lesions; thus, it was not selected. For these reasons, reduced-dose AZA monotherapy was restarted again, and AZA-associated AEs were managed by short-term hospitalization. While the present patient was expected to have an approximately 2-year survival after starting AZA treatment, based on the result of the AZA-001 phase III trial for higher-risk MDS (median overall survival of 24.5 months) [5], he received 21 cycles of AZA treatment in total and eventually survived for 49 months despite developing MS.

To our knowledge, there are 10 reported cases in which MS including leukemia cutis (LC), a phenotype of 


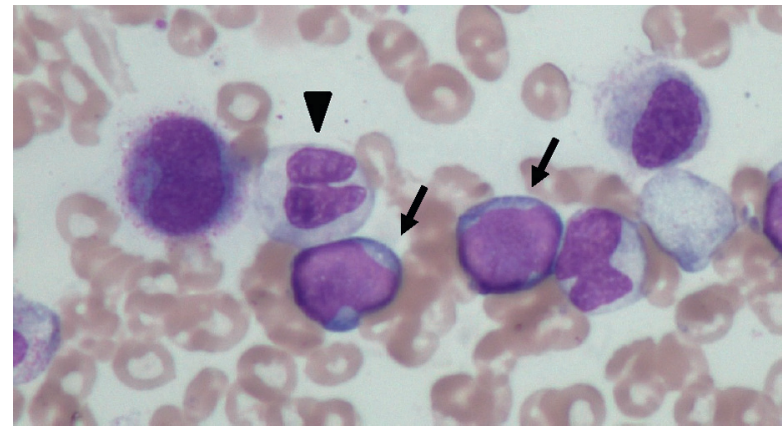

(a)

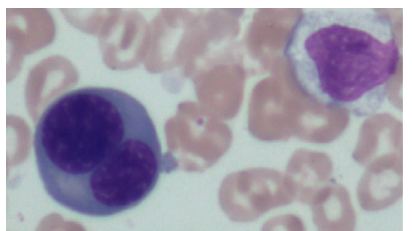

(b)

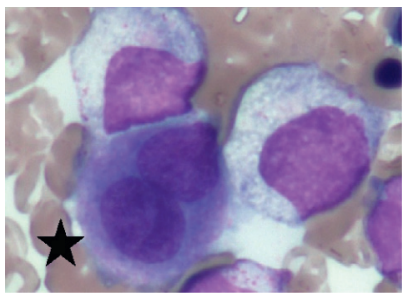

(c)

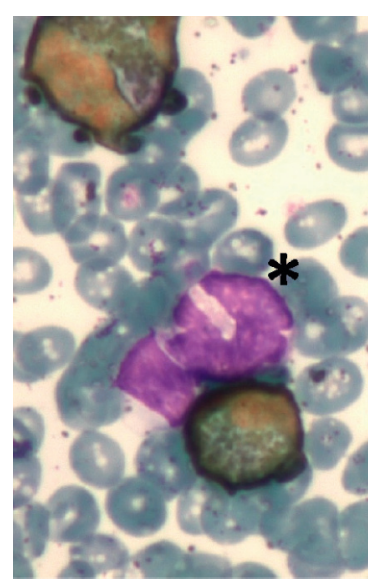

(d)

Figure 1: Microscopic findings of the bone marrow smears. Bone marrow aspirate smears (May-Giemsa staining; magnification: $\times 400$ ) showed (a) myeloblasts (arrows) and a hyposegmented mature neutrophil (arrowhead), (b) a binucleated erythroblast, and (c) a micromegakaryocyte (indicated with a star). (d) Myeloperoxidase staining (magnification: $\times 400$ ) of the bone marrow cells showed a hypogranular neutrophil (indicated with an asterisk).

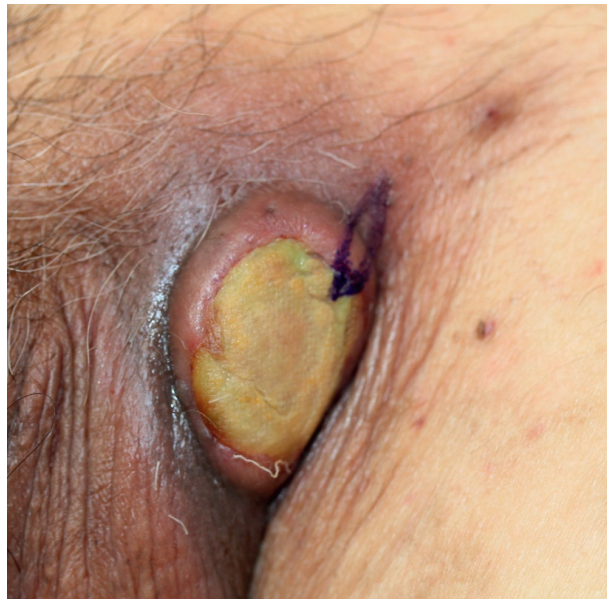

(a)

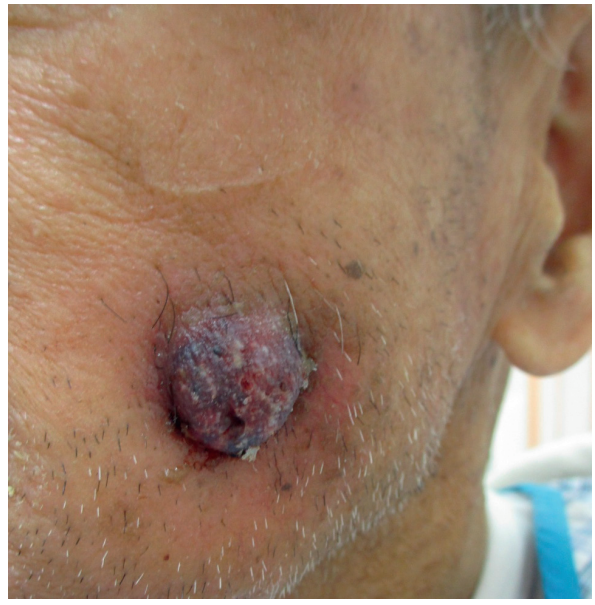

(b)

Figure 2: Cutaneous tumor lesions. (a) A painful cutaneous tumor, the top of which showed yellow-colored necrosis, which developed at the left groin 8 months after the second discontinuation of azacitidine. (b) Another cutaneous tumor, which appeared on the left cheek one month after the development of the first cutaneous lesion at the left groin.

extramedullary leukemia induced by the infiltration of leukemic cells into the epidermis, the dermis, or the subcutis [18], was successfully treated with AZA [8-13]. The clinical characteristics of the cases are shown in Table 1. Aside from two cases, most were elderly patients; our patient was the oldest. In all of these cases, AZA treatment was performed for MS that developed in a patient with preceding hematological malignancies (MDS, chronic myelomonocytic leukemia 


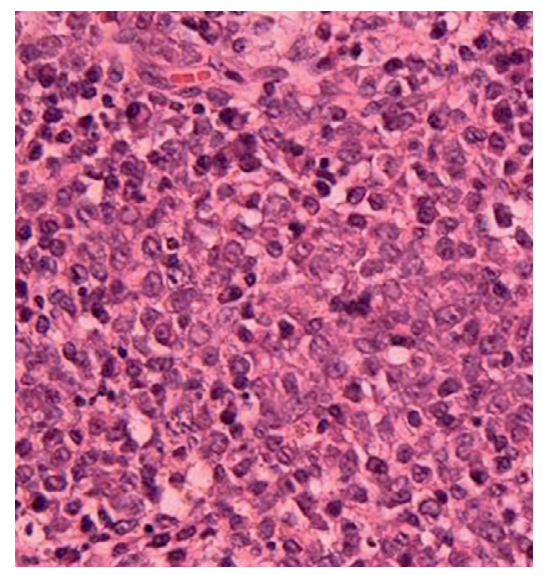

(a)

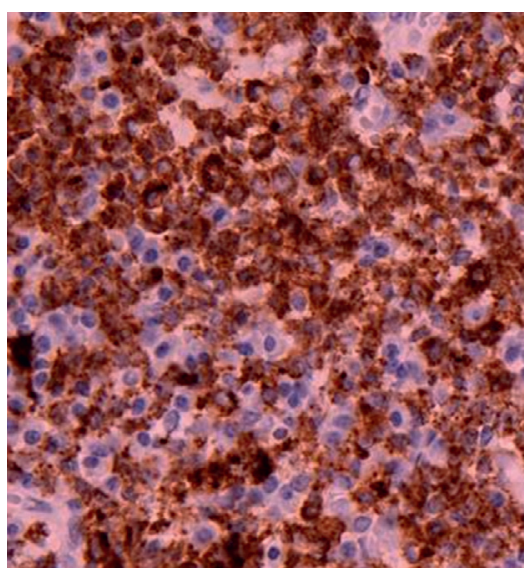

(b)

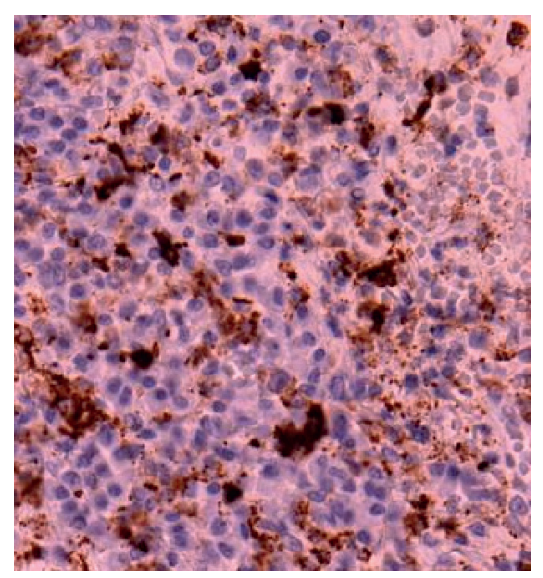

(c)

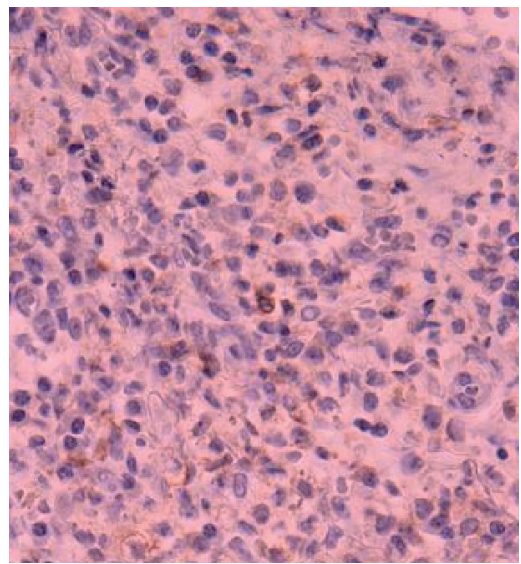

(d)

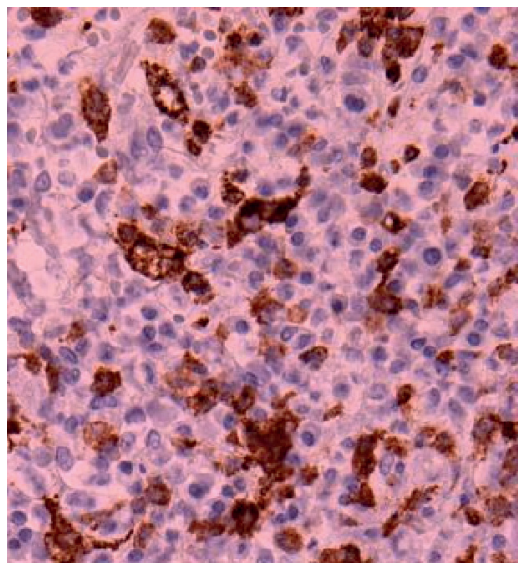

(e)

Figure 3: The histological findings of the tumor located in the left groin. A biopsy specimen showed the proliferation of tumor cells with a high nuclear/cytoplasmic ratio on hematoxylin and eosin staining $(\times 20)($ a). Immunohistochemical staining $(\times 20)$ of tumor cells was positive for myeloperoxidase (b), partially positive for cluster of differentiation (CD) 68 (c), negative for CD4 (d), and negative for CD123 (e).

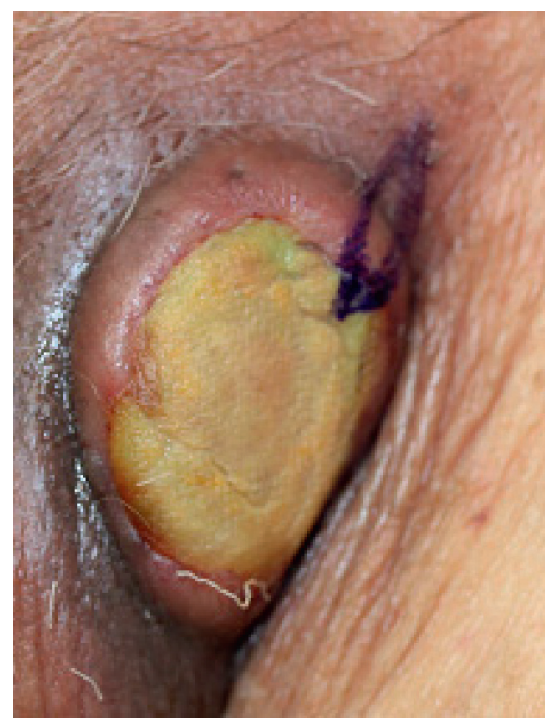

(a)

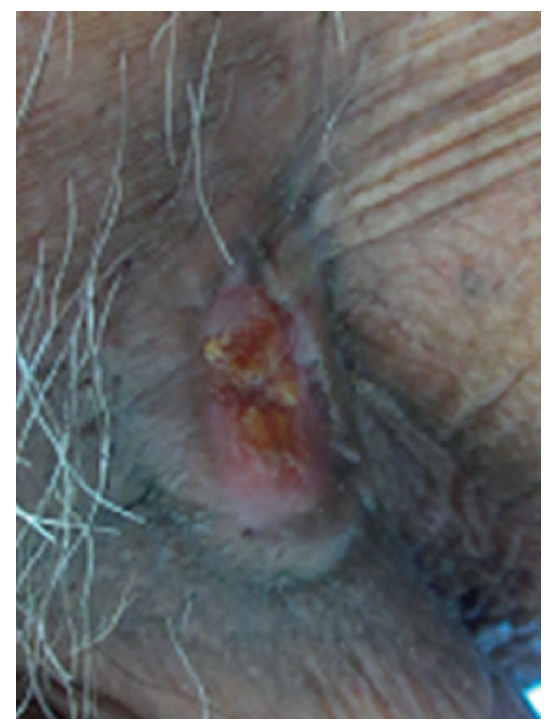

(b)

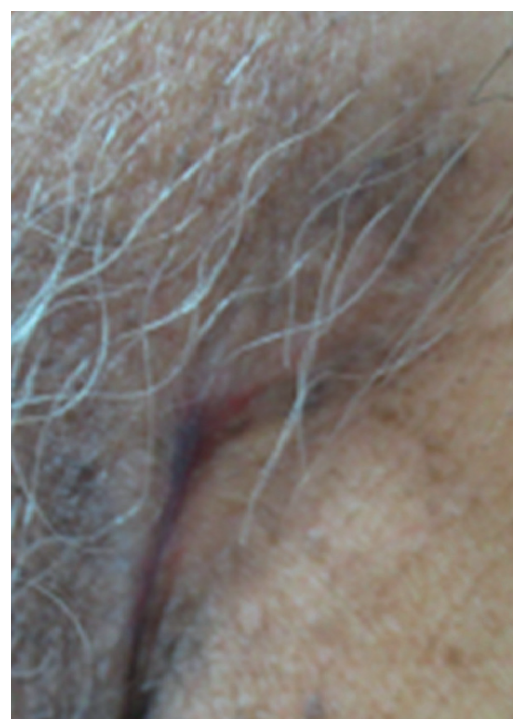

(c)

Figure 4: Continued. 


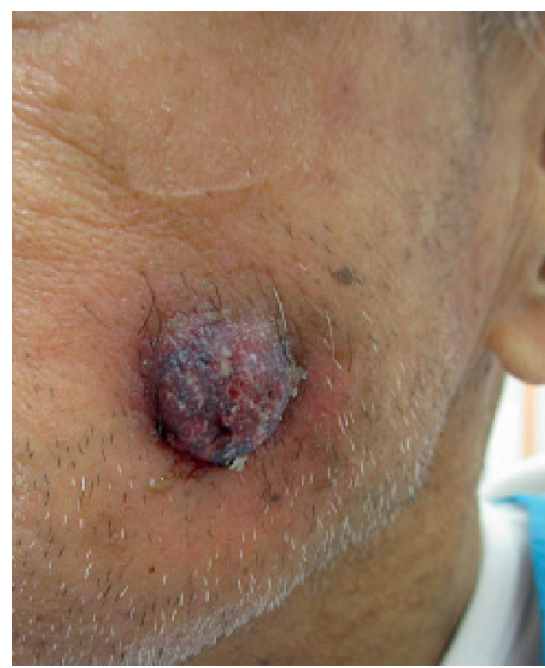

(d)

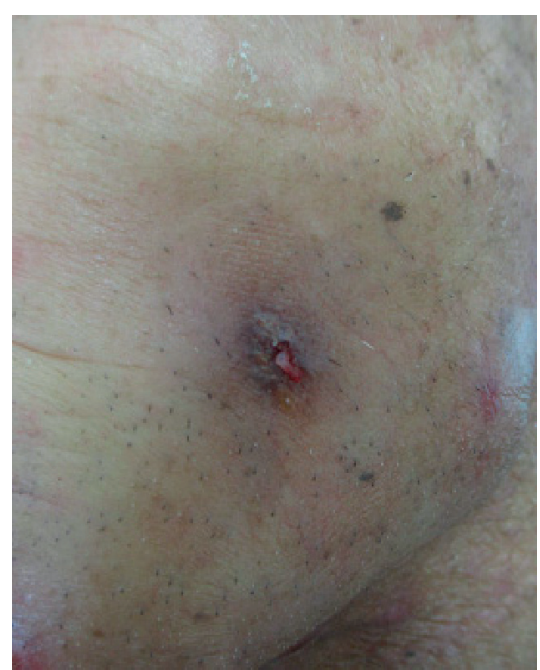

(e)

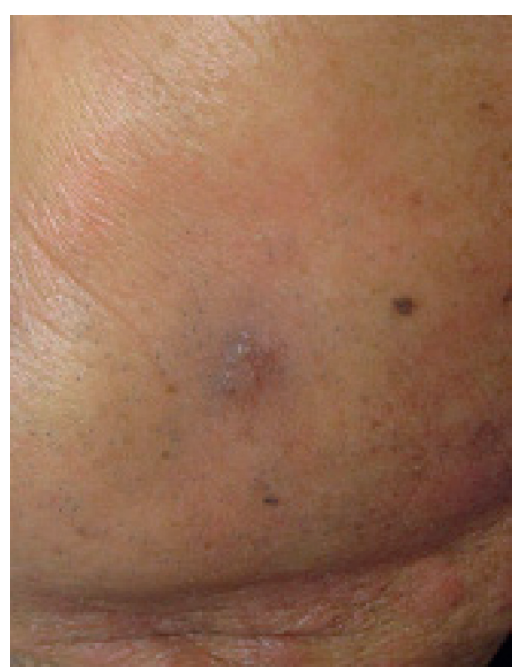

(f)

Figure 4: The response of cutaneous myeloid sarcoma (MS) to treatment with azacitidine. An MS located at the left groin before the first (6th in total) cycle of azacitidine retreatment (a). Before the second (7th in total) cycle (b). After the second cycle (c). An MS on the left cheek before the first cycle (d). Before the second cycle (e). After the second cycle (f).

TABLE 1: The clinical characteristics of cases of myeloid sarcoma that were successfully treated with azacitidine.

\begin{tabular}{|c|c|c|c|c|c|c|c|c|}
\hline $\begin{array}{l}\text { Case/ } \\
\text { reported } \\
\text { year }\end{array}$ & $\begin{array}{c}\text { Age/ } \\
\text { sex }\end{array}$ & $\begin{array}{c}\text { Diagnosis at } \\
\text { development of } \\
\text { MS }\end{array}$ & Sites of origin & Treatment for MS & $\begin{array}{l}\text { Cycles } \\
\text { of AZA } \\
\text { for MS }\end{array}$ & $\begin{array}{l}\text { Maximum } \\
\text { response of AZA } \\
\text { for MS }\end{array}$ & $\begin{array}{c}\text { Outcome } \\
\text { (cause of } \\
\text { death) }\end{array}$ & Reference \\
\hline $1(2013)$ & $62 / \mathrm{M}$ & CMML type-2 & Right humerus & $\begin{array}{c}\text { AZA }\left(75 \mathrm{mg} / \mathrm{m}^{2} \times 7\right. \\
\text { days })+\mathrm{RT}(25 \mathrm{~Gy})\end{array}$ & $6^{*}$ & Decreased in size & Alive & {$[8]$} \\
\hline $2(2013)$ & $34 / \mathrm{M}$ & $\begin{array}{l}\text { Monoblastic } \\
\text { leukemia cutis }\end{array}$ & $\begin{array}{l}\text { Multiple skin } \\
\text { nodules, groin } \\
\text { mass }\end{array}$ & $\begin{array}{l}\text { IDR }+ \text { Ara C followed by } \\
\text { allo-HSCT } \longrightarrow \text { CLAG } \\
\text { followed by DLI and } \\
\text { RT } \longrightarrow \text { a cycle of AZA } \\
\left(32 \mathrm{mg} / \mathrm{m}^{2} \times 5 \text { days }\right) \longrightarrow 4 \\
\text { cycles of AZA }(75 \mathrm{mg} / \\
\left.\mathrm{m}^{2} \times 7 \text { days }\right) \longrightarrow \mathrm{RT}\end{array}$ & 5 & Decreased in size & $\begin{array}{c}\text { Died } \\
\text { (multiorgan } \\
\text { failure) }\end{array}$ & [9] \\
\hline $3(2013)$ & $39 / \mathrm{F}$ & $\begin{array}{l}\text { Relapse of } \\
\text { AML-M2 after } \\
\text { allo-HSCT }\end{array}$ & Gingiva & $\begin{array}{l}\text { FLAG with } \\
\mathrm{GO} \longrightarrow \text { FLAG and } \\
\mathrm{DLI} \underset{\mathrm{m}}{\longrightarrow} \mathrm{AZA}(75 \mathrm{mg} / \\
\left.\mathrm{m}^{2} \times 7 \text { days }\right)\end{array}$ & $17^{*}$ & $\begin{array}{l}\text { Clinical } \\
\text { resolution }\end{array}$ & Alive & [9] \\
\hline $4(2015)$ & $72 / \mathrm{M}$ & MDS EB-2 & $\begin{array}{l}\text { Disseminated } \\
\text { skin papules } \\
\text { (LC) }\end{array}$ & $\begin{array}{l}36 \text { cycles of AZA }(75 \mathrm{mg} / \\
\left.\mathrm{m}^{2} \times 5 \text { days }\right) \text { for } \\
\text { MDS } \longrightarrow 41 \text { cycles of the } \\
\text { same dose of AZA after } \\
\text { the onset of LC }\end{array}$ & $41^{*}$ & $\begin{array}{l}\text { Pathological } \\
\text { resolution }\end{array}$ & Alive & {$[10]$} \\
\hline $5(2015)$ & $78 / \mathrm{M}$ & MDS MLD & $\begin{array}{l}\text { Multiple skin } \\
\text { lesions (LC) }\end{array}$ & $\begin{array}{c}\text { AZA }\left(75 \mathrm{mg} / \mathrm{m}^{2} \times 7\right. \\
\text { days }) \longrightarrow 6-\mathrm{MP}\end{array}$ & 7 & $\begin{array}{l}\text { Clinical } \\
\text { resolution }\end{array}$ & Died (N/A) & {$[10]$} \\
\hline $6(2015)$ & $76 / \mathrm{M}$ & CMML type-1 & $\begin{array}{l}\text { Multiple skin } \\
\text { lesions (LC) }\end{array}$ & $\begin{array}{l}9 \text { cycles of AZA }(75 \mathrm{mg} / \\
\left.\mathrm{m}^{2} \times 5 \text { days }\right) \text { for } \\
\text { CMML } \longrightarrow 4 \text { cycles of } \\
\text { AZA }\left(75 \mathrm{mg} / \mathrm{m}^{2} \times 7\right. \\
\text { days) after the onset of } \\
\text { LC }\end{array}$ & 4 & Regression of LC & Died (N/A) & [10] \\
\hline $7(2016)$ & $80 / \mathrm{F}$ & $\mathrm{MDS} \longrightarrow \mathrm{AML}$ & Left eyelid & $\begin{array}{c}\mathrm{CAG} \underset{\left.\mathrm{m}^{2} \times 7 \text { days }\right)}{\longrightarrow} \text { AZA }(75 \mathrm{mg} / \\
\text { ( }\end{array}$ & $\begin{array}{c}\text { At least } \\
1\end{array}$ & Decreased in size & $\begin{array}{l}\text { Died (AML } \\
\text { progression) }\end{array}$ & [11] \\
\hline $8(2017)$ & $71 / \mathrm{F}$ & MDS EB-2 & $\begin{array}{l}\text { Nasopharynx, } \\
\text { tonsil, spleen, } \\
\text { multiple lymph } \\
\text { nodes, skin }\end{array}$ & $\begin{array}{l}\mathrm{DNR}+\text { Ara } \mathrm{C} \longrightarrow \mathrm{AZA} \\
(100 \mathrm{mg} / \text { body } \times 7 \text { days } \\
\text { as maintenance therapy })\end{array}$ & $20^{*}$ & $\begin{array}{l}\text { Skin: clinical and } \\
\text { radiological } \\
\text { resolution; others: } \\
\text { a marked } \\
\text { reduction in the } \\
\text { FDG uptake on } \\
\text { PET-CT }\end{array}$ & Alive & {$[12]$} \\
\hline
\end{tabular}


TABLE 1: Continued.

\begin{tabular}{|c|c|c|c|c|c|c|c|c|}
\hline $\begin{array}{l}\text { Case/ } \\
\text { reported } \\
\text { year }\end{array}$ & $\begin{array}{l}\text { Age/ } \\
\text { sex }\end{array}$ & $\begin{array}{c}\text { Diagnosis at } \\
\text { development of } \\
\text { MS }\end{array}$ & Sites of origin & Treatment for MS & $\begin{array}{l}\text { Cycles } \\
\text { of AZA } \\
\text { for MS }\end{array}$ & $\begin{array}{l}\text { Maximum } \\
\text { response of AZA } \\
\text { for MS }\end{array}$ & $\begin{array}{c}\text { Outcome } \\
\text { (cause of } \\
\text { death) }\end{array}$ & Reference \\
\hline 9 (2018) & $70 / \mathrm{F}$ & $\begin{array}{c}\text { Therapy-related } \\
\text { MDS (MDS-RS- } \\
\text { MLD) }\end{array}$ & $\begin{array}{l}\text { Multiple skin } \\
\text { lesions (LC) }\end{array}$ & $\begin{array}{l}\text { A cycle of AZA }(75 \mathrm{mg} / \\
\left.\mathrm{m}^{2}\right) \longrightarrow 6 \text { cycles of } \\
\text { biomodulatory therapy: } \\
\text { AZA ( } 75 \mathrm{mg} / \text { body } \times 7 \\
\text { days), pioglitazone and } \\
\text { ATRA }\end{array}$ & 7 & $\begin{array}{l}\text { Clinical } \\
\text { resolution }\end{array}$ & $\begin{array}{l}\text { Died (AML } \\
\text { progression) }\end{array}$ & {$[13]$} \\
\hline $\begin{array}{l}10 \\
\text { (present } \\
\text { case) }\end{array}$ & $89 / \mathrm{M}$ & MDS EB-2 & Skin & $\begin{array}{c}\mathrm{AZA}\left(37.5 \mathrm{mg} / \mathrm{m}^{2} \times 7\right. \\
\text { days })\end{array}$ & 16 & $\begin{array}{l}\text { Clinical } \\
\text { resolution }\end{array}$ & $\begin{array}{l}\text { Died (AML } \\
\text { progression) }\end{array}$ & $\mathrm{N} / \mathrm{A}$ \\
\hline
\end{tabular}

F: female; M: male; MS: myeloid sarcoma; CMML: chronic myelomonocytic leukemia; MDS: myelodysplastic syndrome; AML: acute myeloid leukemia; EB: excess blasts; AZA: azacitidine; RT: radiotherapy; Ara C: cytarabine; CAG: cytarabine, aclarubicin, and granulocyte colony-stimulating factor (G-CSF); DNR: daunorubicin; FDG: fluorodeoxyglucose; PET-CT: positron emission tomography-computed tomography; N/A: not available; LC: leukemia cutis; MLD: multilineage dysplasia; IDR: idarubicin; allo-HSCT: allogeneic hematopoietic stem-cell transplantation; CLAG: cladribine, high-dose cytarabine, and G-CSF; DLI: donor lymphocyte infusion; FLAG: fludarabine, high-dose cytarabine, and G-CSF; GO: gemtuzumab ozogamicin; 6-MP: 6-mercaptopurine; MDS-RS: MDS with ring sideroblasts; ATRA: all-trans-retinoic acid. * "Ongoing."

(CMML), monoblastic LC, or AML). AZA treatment was effective for MS originating at various sites; 7 cases (including our case) involved skin lesions. Four cases (cases 1 and 7-9) with MS were successfully treated with AZA in combination with sequential radiotherapy, multidrug chemotherapy, or biomodulatory drugs. One of the 4 cases (case 8) was treated with AZA as a maintenance therapy. Including the present case-in which AZA monotherapy was administered for remission induction and maintenance therapy-six cases (cases 2-6 and 10) with MS were successfully treated with AZA monotherapy, and five of them had skin leukemic lesions. MS resolved clinically, radiologically, or pathologically with AZA treatment in six cases (cases 3-5 and 8-10). One to 41 cycles of AZA therapy were performed for the 10 patients with MS; 6 of the patients eventually died of the progression of AML or other causes. The dose of AZA was reduced in 4 cases (cases 2, 4, 9, and 10) or modified in 1 case (case 8) among the 10 patients, and the present patient received the lowest dose of AZA ( $37.5 \mathrm{mg} / \mathrm{m}^{2}$ for 7 days) among the cases with repeated treatment for a long period. From these findings, AZA probably has some benefit for MS in a certain group of patients with myeloid malignancies.

Sporadic case studies [19-23] have reported that decitabine-another hypomethylating agent that is used for the treatment of MDS or for the treatment of elderly patients with AML who are not eligible for standard chemotherapy in Western countries-was effective for treating MS in patients with myeloid malignancies (e.g., AML or CMML). Some of those cases with MS involved the skin $[19,22]$, similar to our case. As shown in Table 1, successful treatment with AZA in MS patients with involvement of the skin or with LC has also been reported $[9,10,12,13]$. Thus, hypomethylating agents may have some effects in certain patients with MS, including patients who develop cutaneous lesions.

In this case, the appearance of blasts in peripheral blood was observed after AZA treatment, which eventually led to the progression of leukemia, but the exacerbation of the skin lesions was not observed during the treatment. The first reason for this issue would be that a dose of sufficient intensity for the marrow or peripheral leukemic cells could not be maintained due to the dose reduction and the prolonged treatment interval ( $>4$ weeks). Second, the activation of the immune system by AZA treatment may contribute to the antitumor effect on the skin MS lesions. It has been reported that AZA induces cytotoxic CD8 T cells for some tumor antigens, such as melanoma-associated antigens (MAGE antigens) and Wilm's tumor antigen 1 [24]. In addition, it has been reported that AZA and valproate upregulate MAGE antigens in AML cell lines [25]. Antigen-presenting cells, such as dendritic cells, which are necessary for the activation of antigen-specific cytotoxic T cells, are abundant in the skin. Thus, leukemic cells in the MS lesions on the skin might be controlled by not only the inhibition of DNA synthesis by AZA treatment but also by the antileukemic effect of the activation of cytotoxic T cells against the leukemia-specific antigens. Further accumulation of such cases is required to clarify this issue.

However, a case of LC has been reported in a patient with acute myelomonocytic leukemia on AZA treatment [26]. That case was considered refractory to the AZA treatment. The responsiveness of cutaneous lesions of MDS/AML to AZA treatment might differ by disease status or histology of underlying disease. Physicians should consider the possibility of such a case developing.

We did not have a good treatment plan for this patient other than repeating the treatment with AZA. Venetoclax, which is an inhibitor of the antiapoptotic BCL2 protein, is reported to be clinically beneficial in hypomethylating agent(HMA-) resistant patients with MDS/AML in combination with an HMA [27]. While venetoclax is not currently available for patients with MDS/AML in our country, combination therapy of venetoclax and AZA will likely be a good treatment option for patients such as the present case.

\section{Conclusion}

We reported a case of MS that developed in an elderly patient with MDS, which was successfully treated with AZA monotherapy for a 22-month period, despite a reduction in the dose. Although further accumulation of such cases is 
needed, treatment with AZA should be considered as a potential treatment strategy when MS develops in patients with myeloid malignancies, such as MDS, especially elderly patients who are ineligible for intensive treatment. If an effect on MS is confirmed in such cases, AZA treatment should be continued as much as possible.

\section{Data Availability}

The data supporting the findings of this study are available from the corresponding author upon reasonable request.

\section{Ethical Approval}

The authors declare that this work was performed with all due respect to the code of ethics.

\section{Consent}

Written informed consent was obtained from the family of the patient for publication of this case report and any accompanying images.

\section{Conflicts of Interest}

The authors declare no conflicts of interest in association with the present study.

\section{References}

[1] S. A. Pileri, S. Ascani, M. C. Cox et al., "Myeloid sarcoma: clinico-pathologic, phenotypic and cytogenetic analysis of 92 adult patients," Leukemia, vol. 21, no. 2, pp. 340-350, 2007.

[2] D. A. Arber, A. Orazi, R. Hasserjian et al., "The 2016 revision to the World Health Organization classification of myeloid neoplasms and acute leukemia," Blood, vol. 127, no. 20, pp. 2391-2405, 2016.

[3] K. Kant Sahu, A. Adrian Sherif, A. Kumar Mishra et al., "Testicular myeloid sarcoma: a systematic review of the literature," Clinical Lymphoma, Myeloma \& Leukemia, vol. 19, pp. 603-618, 2019.

[4] R. Bakst, A. Powers, and J. Yahalom, "Diagnostic and therapeutic considerations for extramedullary leukemia," Current Oncology Reports, vol. 22, no. 7, p. 75, 2020.

[5] P. Fenaux, G. J. Mufti, V. E. Santini et al., "Efficacy of azacitidine compared with that of conventional care regimens in the treatment of higher-risk myelodysplastic syndromes: a randomised, open-label, phase III study," The Lancet Oncology, vol. 10, no. 3, pp. 223-232, 2009.

[6] T. Bernal, P. Martínez-Camblor, P. Martínez-Camblor et al., "Effectiveness of azacitidine in unselected high-risk myelodysplastic syndromes: results from the Spanish registry," Leukemia, vol. 29, no. 9, pp. 1875-1881, 2015.

[7] A. Nakaya, S. Fujita, A. Satake et al., "Evaluation of azacitidine in patients with transplant-ineligible myelodysplastic syndromes and acute myeloid leukemia with myelodysplasiarelated changes in a Japanese clinical setting," Oncology Letter, vol. 19, no. 2, pp. 1317-1321, 2020.

[8] A. Serrao, G. Loglisci, A. Salaroli, I. Zacheo, G. Alimena, and M. Breccia, "Azacitidine followed by radiotherapy as effective treatment for chronic myelomonocytic leukemia with extramedullary localization," Leukemia \& Lymphoma, vol. 54, no. 2, pp. 411-412, 2013.
[9] A. Antar, Z. K. Otrock, M. Kharfan-Dabaja et al., "Azacitidine in the treatment of extramedullary relapse of AML after allogeneic hematopoietic cell transplantation," Bone Marrow Transplantation, vol. 48, no. 7, pp. 994-995, 2013.

[10] I. María Stefania, M. Carolina, C. Heras et al., "Leukemia cutis in myelodysplastic syndrome and chronic myelomonocytic leukemia patients treated with adjusted dose 5-azacitidine," European Journal of Dermatology, vol. 25, pp. 622-623, 2015.

[11] H. Kang, Y. Takahashi, E. Takahashi et al., "Myeloid sarcoma in an eyelid that developed during chemotherapy for acute myeloid leukemia," Case Reports in Ophthalmology, vol. 7, no. 1, pp. 25-29, 2016.

[12] T. Kakizaki, T. Ushiki, M. Masuko et al., "Successful 5-azacytidine treatment of myeloid sarcoma and leukemia cutis associated with myelodysplastic syndrome A case report and literature review," Medicine, vol. 96, no. e7975, p. 36, 2017.

[13] D. Heudobler, S. Klobuch, S. Thomas et al., "Cutaneous leukemic infiltrates successfully treated with biomodulatory therapy in a rare case of therapy-related high risk MDS/AML," Frontier Pharmacology, vol. 9, p. 1279, 2018.

[14] P. Greenberg, C. Cox, M. M. LeBeau et al., "International scoring system for evaluating prognosis in myelodysplastic syndromes," Blood, vol. 89, no. 6, pp. 2079-2088, 1997.

[15] P. L. Greenberg, H. Tuechler, J. Schanz et al., "Revised International prognostic scoring system for myelodysplastic syndromes," Blood, vol. 120, no. 12, pp. 2454-2465, 2012.

[16] N. Akiyama, K. Miyazawa, Y. Kanda et al., "Multicenter phase II trial of vitamin K2 monotherapy and vitamin K2 plus $1 \alpha$ hydroxyvitamin D3 combination therapy for low-risk myelodysplastic syndromes," Leukemia Research, vol. 34, no. 9, pp. 1151-1157, 2010.

[17] D. P. Steensma and R. M. Stone, "Practical recommendations for hypomethylating agent therapy of patients with myelodysplastic syndromes," Hematology/Oncology Clinics of North America, vol. 24, no. 2, pp. 389-406, 2010.

[18] R. L. Bakst, M. S. Tallman, D. Douer, and J. Yahalom, "How I treat extramedullary acute myeloid leukemia," Blood, vol. 118, no. 14, pp. 3785-3793, 2011.

[19] A. Castelli, M. L. Mosca-Siez, A. Patriarca, D. Liscia, and A. Conconi, "Efficacy and safety of decitabine against cutaneous granuloblastic sarcoma: a case report," Annals of $\mathrm{He}$ matology, vol. 97, no. 8, pp. 1485-1486, 2018.

[20] D. Riccomagno, B. M. A. M. Bär, M. Gotthardt, and W. J. F. M. van der Velden, "Activity of decitabine in pericardial myeloid sarcoma," International Journal of Hematology, vol. 108, no. 2, pp. 121-122, 2018.

[21] M. Gornicec, A. Wölfler, S. Stanzel, H. Sill, and A. Zebisch, "Evidence for a role of decitabine in the treatment of myeloid sarcoma," Annals of Hematology, vol. 96, no. 3, pp. 505-506, 2017.

[22] D. P. Steensma and B. B. Friday, "Monocytic skin nodules in chronic myelomonocytic leukemia: clinical response to decitabine therapy," Leukemia \& Lymphoma, vol. 48, no. 8, pp. 1628-1629, 2007.

[23] S. N. Singh, Q. Cao, I. Gojo, A. P. Rapoport, and G. Akpek, "Durable complete remission after single agent decitabine in AML relapsing in extramedullary sites after allo-SCT," Bone Marrow Transplantation, vol. 47, no. 7, pp. 1008-1009, 2012.

[24] O. C. Goodyear, M. Dennis, N. Y. Jilani et al., "Azacitidine augments expansion of regulatory $\mathrm{T}$ cells after allogeneic stem cell transplantation in patients with acute myeloid leukemia (AML)," Blood, vol. 119, no. 14, pp. 3361-3369, 2012.

[25] O. Goodyear, A. Agathanggelou, I. Novitzky-Basso et al., "Induction of a CD8+ T-cell response to the MAGE cancer 
testis antigen by combined treatment with azacitidine and sodium valproate in patients with acute myeloid leukemia and myelodysplasia," Blood, vol. 116, no. 11, pp. 1908-1918, 2010.

[26] A. Kara, A. Akın Belli, V. Karakuş, Y. Dere, and E. Kurtoğlu, "A case of leukemia cutis with acute myeloid leukemia on azacitidine therapy," Turkish Journal of Hematology, vol. 4, pp. 192-193, 2017.

[27] B. Liu, Y. Guo, L. Deng, Y. Qiao, and J. Jian, “The efficacy and adverse events of venetoclax in combination with hypomethylating agents treatment for patients with acute myeloid leukemia and myelodysplastic syndrome: a systematic review and meta-analysis," Hematology (Amsterdam, Netherlands), vol. 25, no. 1, pp. 414-423, 2020. 